\title{
DESAIN LANSKAP SEMPADAN SUNGAI BERBASIS PREFERENSI MASYARAKAT DI SEGMEN JALAN RADAR AURI, JAKARTA TIMUR (Preferenced-based Riparian Landscape Design of Cipinang River in The Radar Auri Street Segment, East Jakarta)
}

\author{
Urfa Adzkia* dan Indung Siti Fatimah \\ Departemen Arsitektur Lanskap, Fakultas Pertanian, Institut Pertanian Bogor, \\ Jl. Meranti Kampus IPB Dramaga, Bogor, 16680.
}

*Penulis korespondensi. Tel: 08979415710. Email: 16.urfa@gmail.com.

\begin{abstract}
Abstrak
Jakarta Timur adalah kota administrasi terluas di provinsi DKI Jakarta. Laju pembangunan kota yang semakin meningkat menyebabkan daya tampung dan daya dukung lingkungan kota semakin menurun sehingga memicu timbulnya permasalahan sosial, ekosistem lingkungan daratan maupun akuatik. Lanskap sempadan Sungai merupakan aspek penting dari konstruksi lanskap perkotaan. Lanskap sempadan Sungai Cipinang memiliki fungsi ekologis, estetika dan sosial. Masyarakat merupakan kunci bagi terciptanya kehidupan sosial yang berkelanjutan dalam sebuah taman lingkungan. Untuk memenuhi kebutuhan masyarakat di taman lingkungan perlu adanya keterlibatan masyarakat sekitar dengan mempelajari preferensi masyarakat sekitar terhadap taman. Oleh karena itu, dibutuhkan desain taman lingkungan berdasarkan preferensi masyarakat sekitar untuk menciptakan sebuah taman lingkungan yang fungsional, estetis, ekologis, dan berkelanjutan. Proses desain lanskap sempadan Sungai Cipinang dilakukan melalui beberapa tahap, yaitu: tahap pengumpulan data, tahap analisis dan sintesiskonsep, dan desain. Konsep yang digunakan dalam taman lingkungan ini adalah Taman Olahraga dan Olah jiwa dengan memilih tanaman kangkung air sebagai konsep desain. Konsep ini dipilih untuk menjaga dan memelihara lingkungan sempadan sungai serta memberikan ruang olahraga, area rekreasi dan meningkatkan interaksi antar masyarakat sekitar. Setelah dilakukan proses desain, dihasilkan 3 model pilihan desain dan satu diantaranya menjadi sebuah siteplan yang digunakan sebagai gambar acuan dalam proses pembuatan gambar kerja. Siteplan dilengkapi dengan gambar tampak potongan, perspektif, detail desain, dan rencana penanaman.
\end{abstract}

Kata kunci: desain, lanskap sempadan sungai, preferensi masyarakat, ekosistem, daya dukung.

\begin{abstract}
East Jakarta is the largest administrative city in the province of DKI Jakarta. The increasing space of urban development causes the capacity and the carrying capacity of the urban environment to decrease, thus triggering the emergence of social problems, ecosystems of the land, and aquatic environment. The riparian landscape is an important aspect of the urban landscape. The riparian landscape of Cipinang River has ecological, aesthetic, and social functions. Community is the key to create sustainable social life in the community park. To know the needs of people in a community park is important as well as in a park design process, it could be grasped through the study of people preferences. Therefore, it is important too to study the community park design based on user preference to create a community park that is functional, aesthetic, ecological, and sustainable. The design process will be carried out through several stages, namely: stage of data collection, analysis and synthesis phase, concepts, and design. The concept is "Olah Raga dan Olah Jiwa" which Water Spinach's form as a design concept. It was chosen in addition to preserving and maintaining the riparian landscape environment, also to provide sports spaces, recreation areas. After the design process is carried out, there will be three models of design choices and one of them will be a siteplan that is used as a reference image in the process of making work drawings. A siteplan will be equipped with section plan, perspective, design details, and planting plan.
\end{abstract}

Keywords: communities preference, design, riparian landscape, carrying capacity, ecosystem.

\section{PENDAHULUAN}

Sungai Cipinang adalah salah satu dari tiga belas sungai di wilayah DKI Jakarta yang mengalir melewati Kotamadya Jakarta Timur dengan hulu sungai Situ Jatijajar Kotamadya Depok dan bermuara di Sungai Sunter. Luas DAS Cipinang $4.526,32$ ha dan panjang sungai $30,165 \mathrm{~km}$. Di wilayah sepanjang sungai ini terdapat berbagai kegiatan seperti kegiatan industri, pertokoan, dan permukiman. Berbagai kegiatan disetiap harinya mengeluarkan limbah ke dalam sungai dan ke 
daerah pinggiran atau sempadan Sungai Cipinang, sehingga kondisi lingkungan semakin menurun.

Tujuan penataan ruang Kecamatan Ciracas, menurut Perda Provinsi DKI Jakarta nomor 1 tahun 2014 pasal 464 yaitu untuk kawasan industri selektif, kawasan Ruang Terbuka Hijau (RTH) melalui pelestarian atau mempertahankan prasarana olahraga dan lahan pemakaman umum, kawasan budidaya pertanian dan prasarana budidaya balai benih ikan, serta pengembangan kawasan permukiman berwawasan lingkungan melalui perbaikan atau peremajaan lingkungan. RTH merupakan salah satu tujuan penataan ruang di daerah Ciracas data dari Dinas Pertamanan dan Pemakaman DKI Jakarta menunjukkan, jumlah RTH di Jakarta Timur sebanyak 539 RTH, meski begitu keseluruhan RTH DKI Jakarta hanya berjumlah 9,98\% dari total luas wilayah. Angka ini masih jauh dari $30 \%$ sesuai dengan UndangUndang nomor 26 tahun 2007 tentang Penataan Ruang.

Salah satu RTH di Kecamatan Ciracas dengan kondisi yang semakin memburuk yaitu RTH Cibubur di Jalan Radar Auri, Kelurahan Cibubur, Kecamatan Ciracas yang terletak di sempadan Sungai Cipinang. RTH tersebut direncanakan diperuntukkan sebagai taman lingkungan tingkat RW. Lokasi RTH tersebut belum memiliki kondisi yang layak untuk sebuah taman karena belum adanya perancangan taman yang ditetapkan, sehingga tapak terlihat seperti lahan tidak terkelola dan bertanamkan tumbuhan liar. Perlu adanya desain taman yang sesuai dengan kondisi lingkungan sempadan sungai.

Pendekatan desain yang berkelajutan dapat menciptakan lingkungan yang kondusif (Jamaludin dkk, 2014). Desain dan penataan seperti ini telah berhasil dilakukan untuk konsep penataan sempadan sungai Ciliwung oleh Himawan dan Santoni (2019) serta oleh Wardiningsih dan Salam (2019). Desain taman yang berkelanjutan membutuhkan keterlibatan masyarakat dengan menemukan kebutuhan dan tuntutan masyarakat (Mahdavinejada dan Abedi, 2011).

Dalam memenuhi kebutuhan desain lanskap sempadan sungai segmen Jalan Radar Auri ini perlu mempelajari persepsi dan preferensi masyarakat sekitar. Preferensi adalah sebuah konsep yang mengasumsikan dan membayangkan pilihan antara alternatif dan peringkat terhadap kepentingan mereka (Grahn dan Stigsdotter, 2010). Oleh karena itu, lahan tersebut sesuai untuk dijadikan sebagai lokasi penelitian yang bertujuan mengkaji potensi dan kendala yang terdapat di tapak dan memberikan desain lanskap sempadan sungai yang tidak hanya dirancang berdasarkan aspek fisik, bio-fisik, dan aspek legal tetapi perlu didesain berbasis preferensi masyarakat sekitar untuk menciptakan lanskap sempadan yang fungsional, ekologis, dan estetis. Tujuan dari penelitian ini yaitu mengidentifikasi potensi dan kendala pada tapak, menyusun konsep desain lanskap sempadan sungai, merancang lanskap sempadan sungai.

\section{METODE PENELITIAN}

\section{Waktu dan Lokasi}

Penelitian dilakukan dari pada Mei-Desember 2018. Penelitian bertempat di Jalan Radar Auri RT 007 RW 014 Kelurahan Cibubur Kecamatan Ciracas, Kota Jakarta Timur. Secara geografis, tapak berada di koordinat $6^{\circ} 22$ '14,6" LS ; 106 53 '01,5” BT (Gambar 1).

\section{Metode Penelitian}

Penelitian dilakukan dengan mengacu pada proses perancangan menurut Gold (1980) dengan penambahan metode preferensi pengguna potensial tapak, dalam melakukan perancangan dibutuhkan inventarisasi data, analisis dan sintesis yang digunakan sebagai acuan untuk menghasilkan sebuah konsep dan desain. Berikut penjabaran metode yang digunakan dalam penelitian ini:

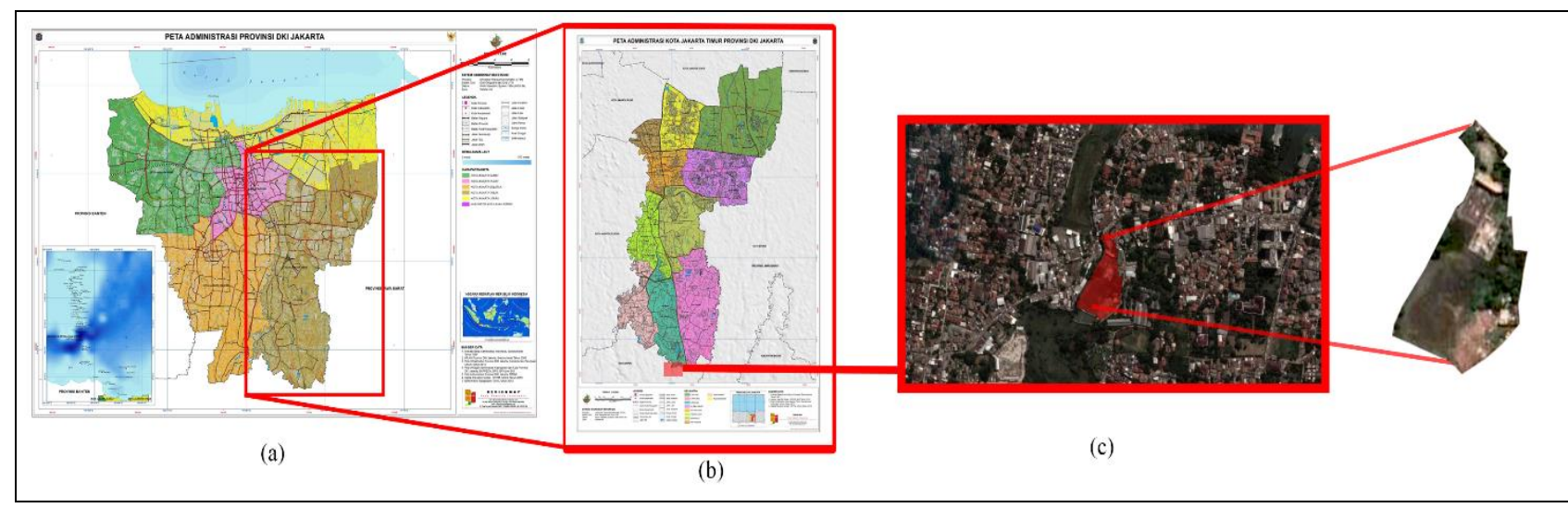

Gambar 1. (a) Peta DKI Jakarta, (b) Peta Jakarta Timur, (c) Tapak penelitian. (Sumber: Petatematikindo.files.wordpress.com, Google Earth. 


\section{Inventarisasi Data}

Tahapan inventarisasi dilakukan pada hari kerja dan libur, dengan pembagian waktu pagi, siang, dan malam. Hal tersebut dilakukan untuk mengetahui beberapa aspek penting seperti aspek hidrologi, drainase, batas tapak, topografi dan kemiringan lahan, kenyamanan iklim mikro dan interaksi sosial. Kuesioner ditujukan kepada masyarakat sekitar tapak. Tahap ini untuk menentukan kebutuhan apa yang diperlukan oleh pengguna potensial tapak sebagai pertimbangan dalam desain.

\section{Analisis dan Sintesis}

Analisis dilakukan berdasarkan data yang sudah terkumpul untuk mendapatkan potensi dan amenity serta mengetahui kendala pada tapak. Tahap ini dilakukan melalui metode analisis deskriptif kualitatif dan analisis spasial. Hasil analisis akan disintesis untuk mendapatkan pemecahan masalah yang akan menghasilkan susunan zonasi serta konsep.

\section{Identifikasi Persepsi Masyarakat}

Analisis ini dilakukan dengan membagikan kuesioner untuk mengetahui persepsi masyarakat terhadap lanskap sempadan sungai yang ekologis sesuai dengan ketentuan legal perundang-undangan di Indonesia. Model perhitungan hasil kuesioner menggunakan skala Likert. Skala Likert merupakan skala yang digunakan untuk mengukur sikap, pendapat, dan persepsi seseorang atau sekelompok orang tentang suatu fenomena sosial (Sugiyono, 2009).Terdapat 5 level yang digunakan dalam skala Likert, yaitu: 1) untuk Sangat tidak setuju, 2) untuk Tidak setuju, 3) untuk Cukup setuju, 4) untuk Setuju, 5) untuk Sangat setuju. Rumus dasar untuk skala Likert:

$$
\mathrm{A}_{\mathrm{i}}=\frac{(\mathrm{a} .5)+(\mathrm{b} .4)+(\mathrm{c} .3)+(\mathrm{d} .2)+(\mathrm{e} .1)}{\text { Jumlah total semua responden }}
$$

Keterangan: $\mathrm{A}_{\mathrm{i}}$ : Persepsi untuk butir petanyaan ke-I, a: Jumlah responden yang memilih jawaban a, b: Jumlah responden yang memilih jawaban b, c: Jumlah responden yang memilih jawaban c, d: Jumlah responden yang memilih jawaban $d$, e: Jumlah responden yang memilih jawaban e.

Tiap nilai pernyataan dari hasil perhitungan masuk dalam salah satu kategori berikut: $1<\mathrm{A}_{\mathrm{i}}<1,8$ : Sangat tidak setuju, $1,81<\mathrm{A}_{\mathrm{i}}<2,6$ : Tidak setuju, 2,61< $\mathrm{A}_{\mathrm{i}}<3,4$ : Cukup setuju, $3,41<\mathrm{A}_{\mathrm{i}}<4,2$ : Setuju, $4,21<\mathrm{A}_{\mathrm{i}}<5$ : Sangat setuju.

Hasil dari perhitungan persepsi masyarakat tersebut akan menunjukkan tingkat kesetujuan masyarakat terhadap beberapa fungsi lanskap sempadan sungai sebagai penyangga antara ekosistem sungai dan daratan yang di tetapkan pada Peraturan Pemerintah Republik Indonesia No. 38
Tahun 2011 Pasal 5 Ayat 5. Dengan mendapatkan kategori fungsi ekologis lanskap diharapkan mampu meningkatkan nilai kesadaran masyarakat dalam menjaga lingkungan lanskap dan mendapatkan desain lanskap sempadan sungai yang sesuai dengan kebutuhan aspek fisik, biofisik, sosial dan aspek legal.

\section{Konsep}

Konsep akan dikembangkan menjadi konsep dasar, konsep desain, konsep pengembangan, konsep vegetasi, konsep sirkulasi, dan konsep pola bentuk. Hasil akhir dari tahap konsep adalah block plan yang dijadikan sebagai acuan untuk pembuatan preliminari desain dan site plan.

\section{Desain}

Desain akan dikembangkan menjadi desain preliminari, desain akhir, dan desain pengembangan.

\section{HASIL DAN PEMBAHASAN}

\section{Kondisi umum}

Tapak memiliki luas sebesar $3563 \mathrm{~m}^{2}$. Kondisi jalan di sekitar tapak tergolong baik karena sudah beraspal dan berbeton, namun kondisi jalan akses ke dalam tapak masih tanah berbatu. Akses dapat dicapai dari dua arah yaitu dari arah selatan dan utara. Bagian barat tapak adalah sungai cipinang dan bagian timur adalah permukiman dan industri kecil. Tapak secara geologis terletak pada dataran rendah yang datar (Gambar 2). Tapak terletak pada ketinggian wilayah 0-20 m dpl. Tapak memiliki kemiringan lereng antara 0-2\%. Menurut Zuidam (1985) kemiringan lereng pada tapak termasuk kategori datar-hampir datar. Elevasi terendah berada pada pinggir bagian barat tapak dan elevasi tertinggi berada pada bagian timur tapak. Kondisi geologi tapak tersusun atas batuan alluvium. Drainase yang terdapat di tapak yaitu drainase permukaan tanah (surface drainage) drainase bawah permukaan tanah (sub-surface drainage). Berdasarkan data dari BPS Kota Administrasi Jakarta Timur: Sub Seksi Meteorologi Halim Perdana Kusuma suhu rata-rata Kecamatan Ciracas tahun 2016 berkisar $27,7^{\circ} \mathrm{C}$ dengan tingat kelembaban udara rata-rata $80 \%$. Rata-rata curah hujan pada Kecamatan Ciracas adalah $270 \mathrm{~mm}$ per bulan di tahun 2016 .

Berdasarkan hasil survey, tanaman yang terdapat dalam tapak pada umumnya merupakan rumput, semak dan pepohonan. Tanaman yang ada pada tapak adalah Ketul (Bidens pilosa), Kaliandra (Calliandra calothyrsus), Kapuk (Ceiba pentandra), Kelapa (Cocos nucifera), Mangga (Mangifera indica), Putri malu (Mimosa pudica), 


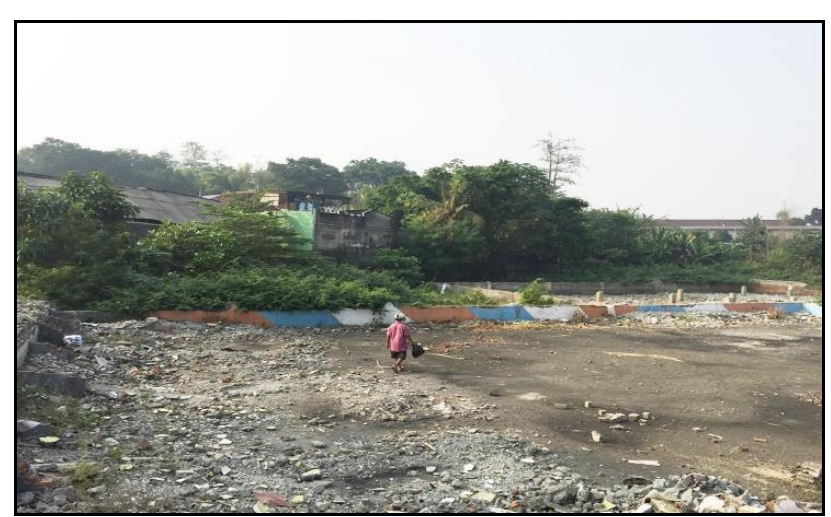

(a)

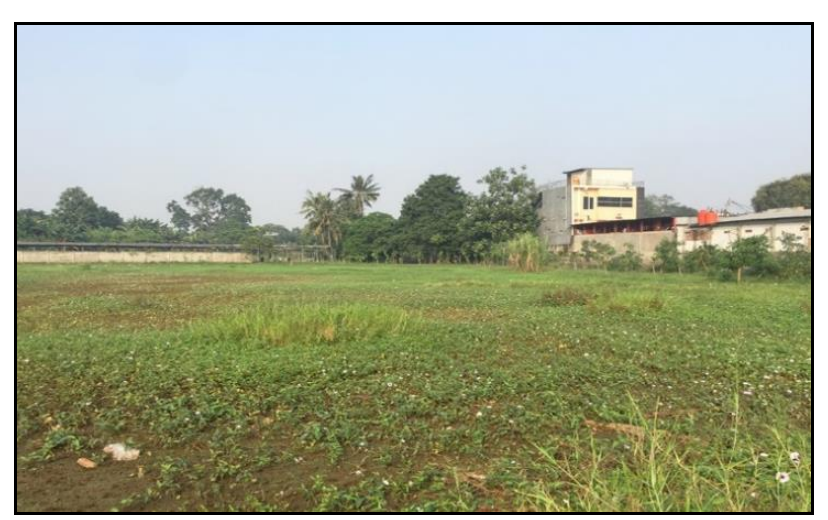

(b)

Gambar 2. Kondisi topografi tapak (a) Topografi datar pada area bekas bangunan, dan (b) Topografi hampir datar pada area hijau, yaitu rawa.

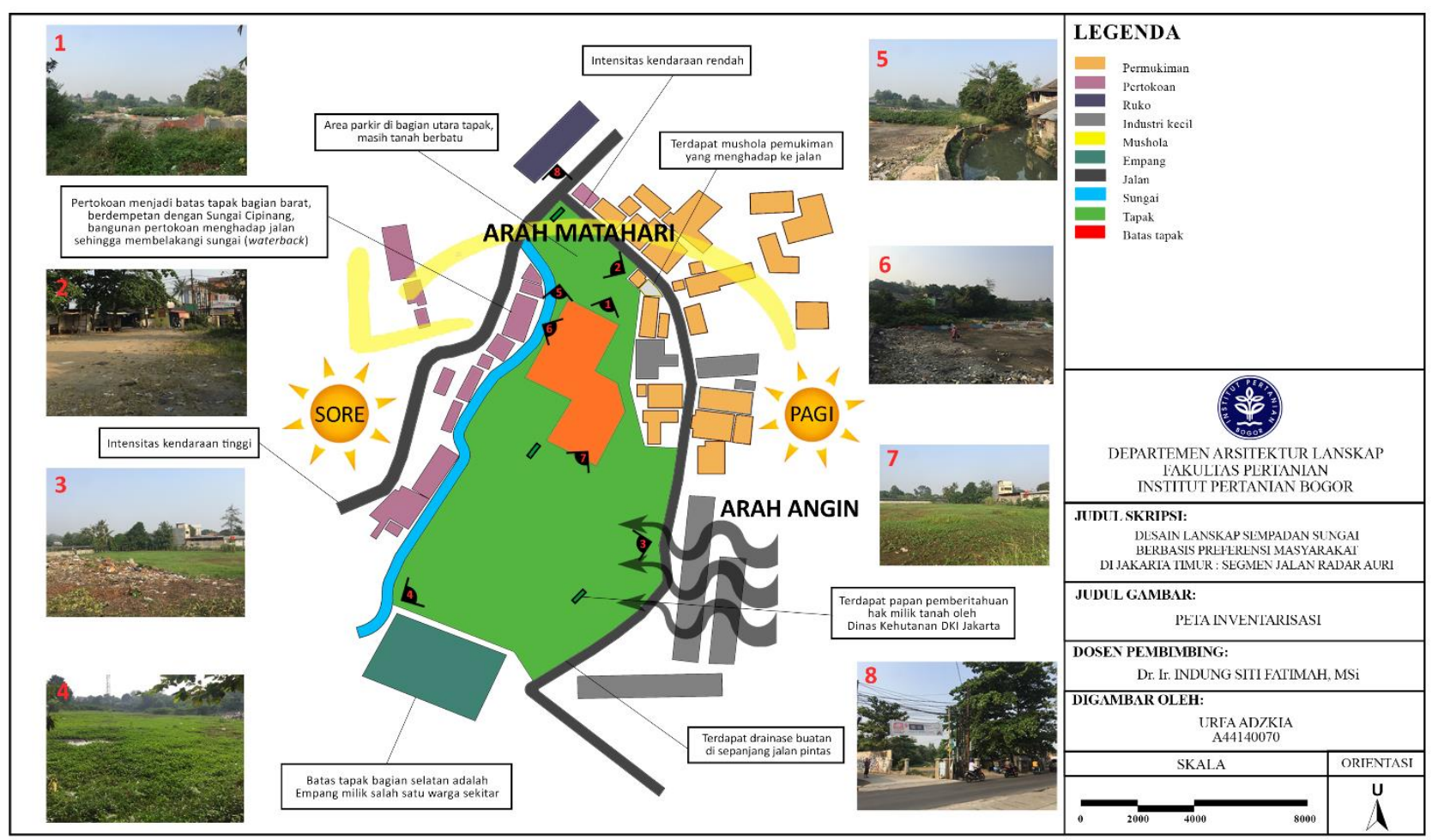

Gambar 3. Peta Inventarisasi.

Pisang (Musa acuminata), Kangkung-kangkungan (Ipomoea aquatica), Morning glory (Ipomoea purpurea), Ketapang (Terminalia catappa). Satwa yang terdapat pada tapak yaitu burung wallet (Collocalia vestita) dan burung gereja (Passer montanus), katak (Bufo melanostictus), dan kadal (Eutropis multifasciata). Tapak dikelola oleh Suku Dinas Pertamanan dan Pemakaman Kota milik Dinas Kehutanan DKI Jakarta. Penyediaan dan pemanfaatan RTH publik ini baru sebatas tahap perencanaan dan pengadaan lahan sehingga belum adanya perancangan teknik, pelaksanaan pembangunan, serta pemanfaatan dan pemeliharaan. Fungsi tapak eksisting hanya digunakan sebagai lahan hijau yang tidak digunakan. Sebelumnya, tapak ini digunakan sebagai arena futsal indoor milik swasta. Pembebasan lahan dengan peruntukkan RTH
Taman pada tapak telah dilakukan oleh Dinas Kehutanan DKI Jakarta sejak tahun 2011. Peta Inventarisasi tapak dapat dilihat pada Gambar 3.

\section{Fisik dan Biofisik}

Hasil analisis fisik dan biofisik tapak yaitu penataan vegetasi eksisting tapak belum dapat mendefinisikan suatu ruang-ruang tertentu, seperti vegetasi yang berfungsi menutupi pemandangan yang tidak diinginkan serta pembentukan ruang dan pandangan. Belum adanya vegetasi untuk pengendalian silau, pengendali erosi, modifikasi bising, dan vegetasi pengarah lalu lintas kendaraan maupun pejalan kaki. Adanya rawa dan semaksemak pada tapak membuat sebagian satwa seperti kadal dan katak hidup sesuai habitat. Hal ini perlu dipertahankan untuk menjaga ekosistem lingkungan sekaligus memberi edukasi tentang hidup 
berdampingan antara manusia dengan alam. Satwa burung cukup banyak ditemukan pada tapak dan perlu dipertahankan.

\section{Aspek Sosial}

Berdasarkan data kuesioner yang didapat, aktivitas yang diinginkan masyarakat adalah berolahraga, berkumpul, serta bersantai. Elemen lanskap yang paling diinginkan adalah elemen tanaman $(80 \%)$. Aktivitas yang diinginkan masyarakat untuk dapat dihadirkan pada taman lingkungan yaitu berolahraga (50). Tema lingkungan yang cocok untuk taman lingkungan pada lanskap sempadan sungai Jalan Radar Auri menurut masyarakat adalah tema modern $(73 \%)$. Hasil kuesioner menunjukkan penilaian masyarakat terhadap PP RI No. 38 Tahun 2011 Pasal 5 Ayat 5 mengenai fungsi-fungsi lanskap sempadan sungai sebagai penyangga antara ekosistem sungai dan daratan, masyarakat dominan sangat setuju dengan peraturan tersebut, dengan hasil ini diharapkan dapat mendorong dan mengubah perilaku masyarakat agar semakin sadar akan pentingnya lanskap sempadan sungai masyarakat serta semakin menjaga lingkungan lanskap sempadan sungai.

\section{Konsep Dasar}

Konsep dasar taman ini adalah "Olah Rawa" yang berarti "Olah Raga dan Jiwa". Keberadaan rawa akan tetap dipertahankan dan menjadi vegetasi dominan yang ditonjolkan pada desain taman ini. Kata "Rawa" ini juga diartikan sebagai "Raga dan Jiwa". Berdasarkan data hasil wawancara, fasilitas yang paling diminati masyarakat yaitu pertama fasilitas untuk tempat berolahraga, kedua adalah tempat untuk bersantai.

Tabel 1. Pembagian ruang.

\begin{tabular}{|c|c|c|c|}
\hline Aktivitas & Sub-aktivitas & Ruang & Persentase Luas \\
\hline \multicolumn{4}{|c|}{ A. Berdasarkan aktivitas sesuai preferensi masyarakat } \\
\hline \multirow[t]{3}{*}{ Berolahraga $(50,00 \%)$} & Lari / jogging & Ruang berolahraga & $20 \%$ \\
\hline & $\begin{array}{l}\text { Pembentukan tubuh (push up, sit up, } \\
\text { back up dan sejenisnya) }\end{array}$ & & \\
\hline & Futsal / basket / bulu tangkis / senam & & \\
\hline \multirow[t]{2}{*}{ Bersantai $(43,00 \%)$} & $\begin{array}{l}\text { Bersantai menikmati pemandangan / } \\
\text { berkumpul }\end{array}$ & Ruang Bersantai & $17.20 \%$ \\
\hline & Bermain anak & $\begin{array}{l}\text { Children } \\
\text { Plavoround }\end{array}$ & \\
\hline Berkumpul $(7,00 \%)$ & Rapat / Acara & Ruang berkumpul & $2.80 \%$ \\
\hline \multirow[t]{2}{*}{ Konservasi } & Keperluan operasi sungai & Jalur inspeksi & $40.00 \%$ \\
\hline & Konservasi & Vegetasi & \\
\hline \multicolumn{4}{|c|}{ B. Berdasarkan cara tempuh masyarakat ke taman } \\
\hline Berjalan kaki $(23,00 \%)$ & Berjalan kaki & $\begin{array}{l}\text { Sirkulasi pejalan } \\
\text { kaki }\end{array}$ & $4.60 \%$ \\
\hline \multirow[t]{2}{*}{ Berkendara roda dua $(67,00 \%)$} & Memarkir sepeda & Shelter sepeda & $13.40 \%$ \\
\hline & Memarkir motor & Tempat parkir motor & \\
\hline \multirow[t]{2}{*}{ Berkendara roda empat $(10,00 \%)$} & Memarkir mobil & Tempat parkir mobil & $2.00 \%$ \\
\hline & & Total & $100 \%$ \\
\hline
\end{tabular}

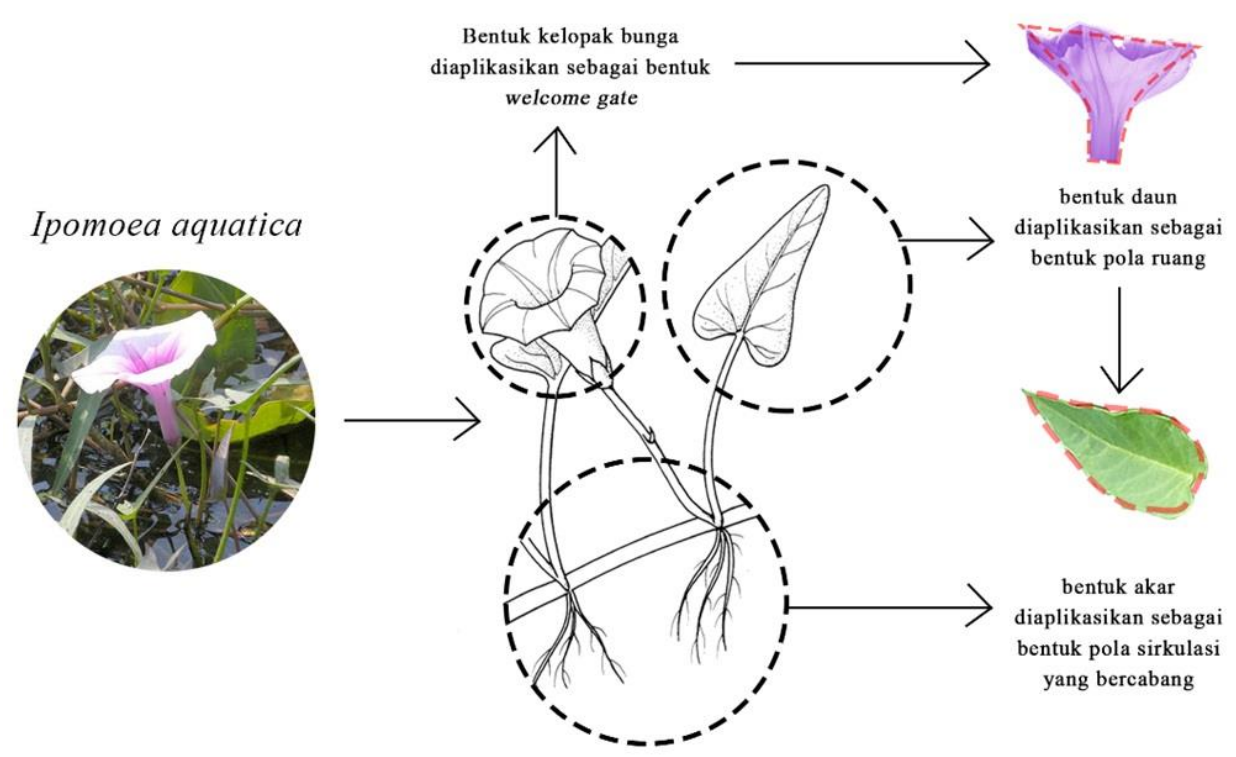

Gambar 4. Konsep desain "Tanaman Kangkung Air". (Sumber: Sites.google.com, Agroekoteknologi08.wordpress.com). 


\section{Konsep Desain}

Konsep desain yang akan digunakan adalah salah satu vegetasi yang dominan pada tapak yaitu "Tanaman Kangkung Air". Kangkung air merupakan salah satu tanaman sayuran yang digunakan oleh suku asli Provinsi Jakarta. Penerapan konsep "Tanaman Kangkung Air" yaitu dengan mengambil bentukan akar dan batang sebagai pola bentuk sirkulasi, bentuk daun diaplikasikan sebagai bentuk pola ruang, bunga dari tanaman kangkung air diaplikasikan sebagai bentuk gate pada welcome area (Gambar 4).

\section{Konsep Pengembangan}

Konsep desain yang dikembangkan meliputi konsep ruang, konsep sirkulasi, konsep vegetasi, konsep fasilitas dan utilitas. Pengembangan konsep dilakukan untuk penyusunan block plan, yang akan dijadikan sebagai acuan desain (Laurie, 1986). Konsep ruang yang akan dikembangkan mengacu pada kegiatan yang akan dihadirkan ke dalam taman. Kegiatan tersebut antara lain; berolahraga, bersantai, bermain, berkumpul, jogging, bersepeda, memarkir kendaraan. Diagram keterhubungan ruang dapat dilihat pada Gambar 5.

Konsep sirkulasi digunakan untuk menghubungkan ruang satu dengan ruang lainnya. Terdapat 3 ruang yang perlu dihubungkan oleh sirkulasi. Sirkulasi di dalam tapak terdiri dari sirkulasi primer dan sekunder. Sirkulasi primer meliputi sirkulasi untuk menghubungkan antar ruang utama. Sirkulasi sekunder merupakan cabang dari sirkulasi primer, sebagai akses untuk mempermudah ke ruang lain. Melihat dari konsep tanaman kangkung air, bentuk akar dapat dikembangkan menjadi pola sirkulasi. Konsep vegetasi pada tapak dipilih berdasarkan fungsi yang dibutuhkan pada masing-masing ruang. Ruang konservasi membutuhkan vegetasi penahan erosi, ruang aktivitas membutuhkan vegetasi penaung, dan jalur pedestrian yang berbatasan langsung dengan jalan membutuhkan vegetasi peredam bising.

\section{Block Plan}

Block plan (Gambar 6) merupakan hasil penggabungan antara preferensi masyarakat, analisis tapak, dan komposit dari pengembangan konsep. Preferensi masyarakat diaplikasikan dalam menentukan ruang-ruang yang akan dihadirkan pada taman. Ruang yang dihadirkan pada taman mampu memfasilitasi masyarakat melakukan aktivitas seperti berolahraga, berkumpul, bersantai, serta bermain. Konsep dasar dan desain akan diaplikasikan dalam bentuk pola tapak. Pola tapak diaplikasikan pada sirkulasi taman yang membentuk seperti morfologi tanaman kangkung air.

\section{Area Berkumpul dan Bersantai}

Area berkumpul terdapat disisi selatan lapangan olahraga, letaknya dekat dengan akses pintu masuk taman sebelah selatan yang dekat dengan area pemancingan. Fasilitas yang diberikan yaitu bangunan ampiteater semi outdoor sebagai tempat berkumpul masyarakat sekitar atau pengguna taman lainnya. Diantara bangunan tersebut dan area bermain anak terdapat lawn yang dapat difungsikan sebagai area berkumpul outdoor dan area bersantai yang memiliki luas $286 \mathrm{~m}^{2}$. Gambar detail engineering design bangunan amphitheater ada pada Gambar 11 dan ilustrasi ampiteater dapat dilihat di Gambar 12.

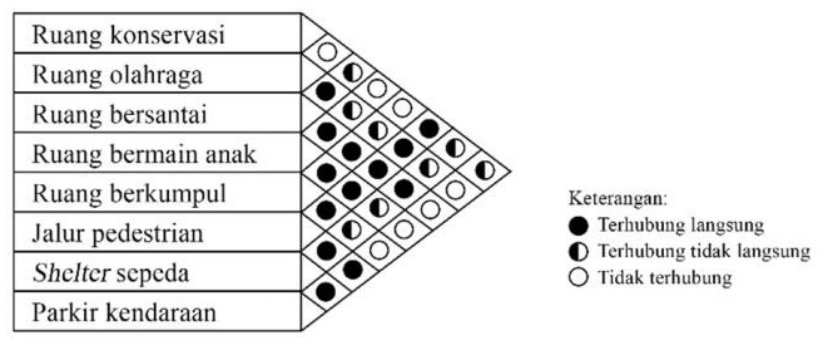

Gambar 5. Diagram keterhubungan ruang.

Tabel 2. Jenis-jenis vegetasi yang akan ditambahkan ke dalam taman.

\begin{tabular}{clll}
\hline No & \multicolumn{1}{c}{ Nama latin } & \multicolumn{1}{c}{ Nama lokal } & \multicolumn{1}{c}{ Fungsi } \\
\hline 1 & Delonix regia & Flamboyan & Peneduh \\
2 & Samanea saman & Trembesi & \\
3 & Terminalia catappa & Ketapang & \\
4 & Salix babilonica & Janda merana & Display \\
5 & Russelia sp. & Air mancur & \\
6 & imperata cylindrica & Alang-alang & Penahan erosi \\
7 & Cymbopogon nardus & Serai wangi & \\
8 & Chrysopogon zizanioides & Akar wangi & \\
9 & Hierochloe odorata & Rumput manis & \\
10 & Tectona grandis & Jati emas & Peredam bising \\
\hline
\end{tabular}




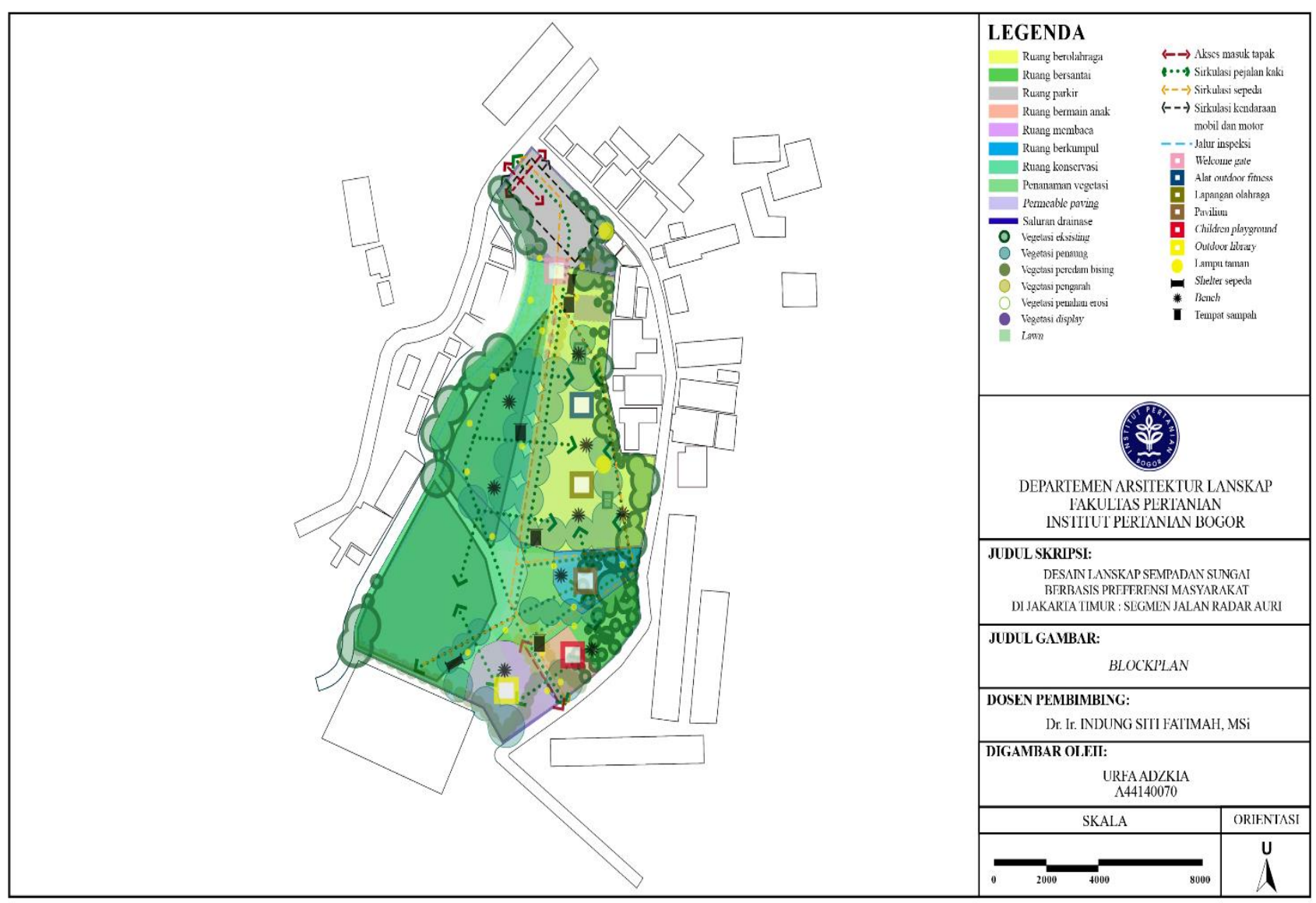

Gambar 6. Blockplan.

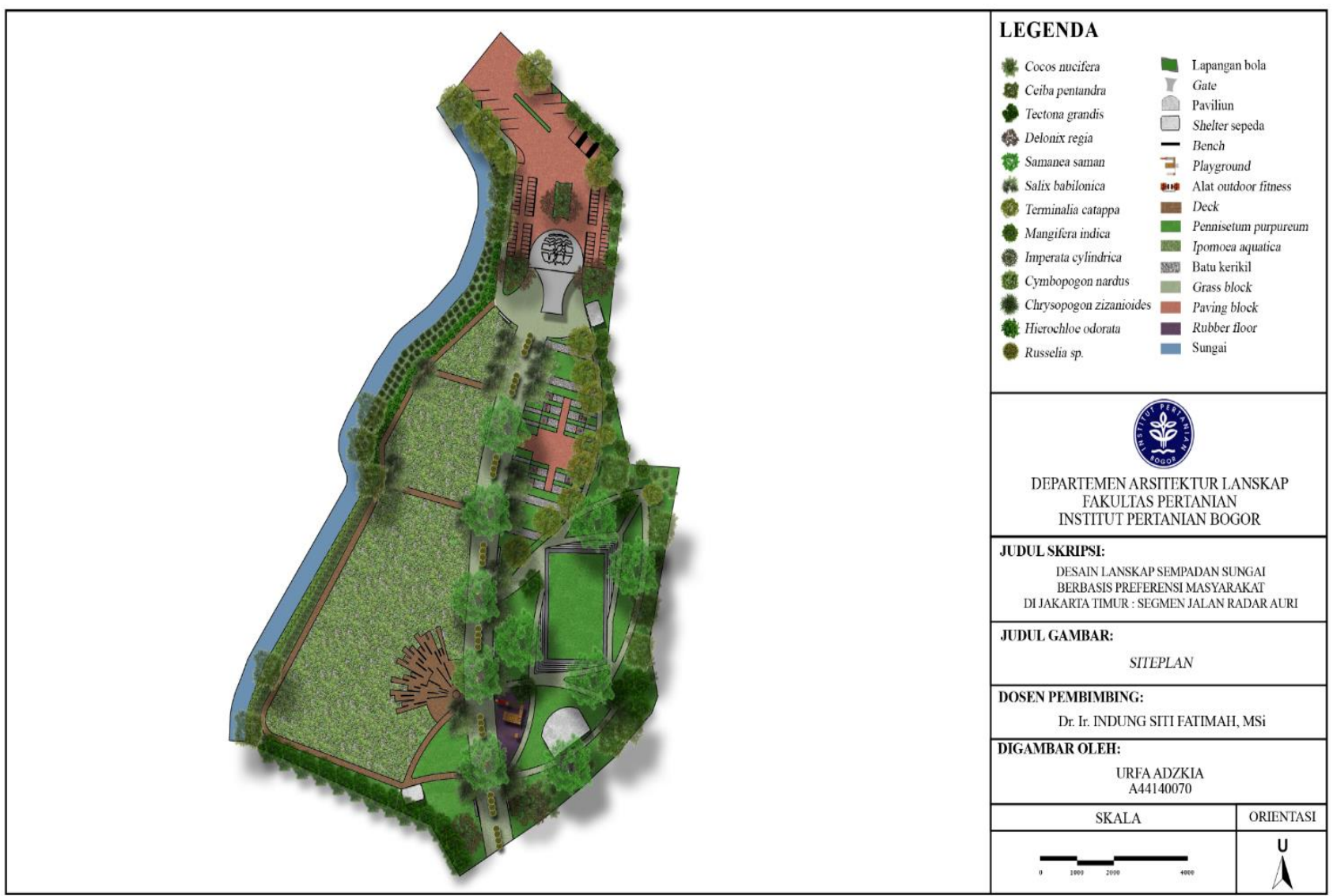

Gambar 7. Siteplan. 


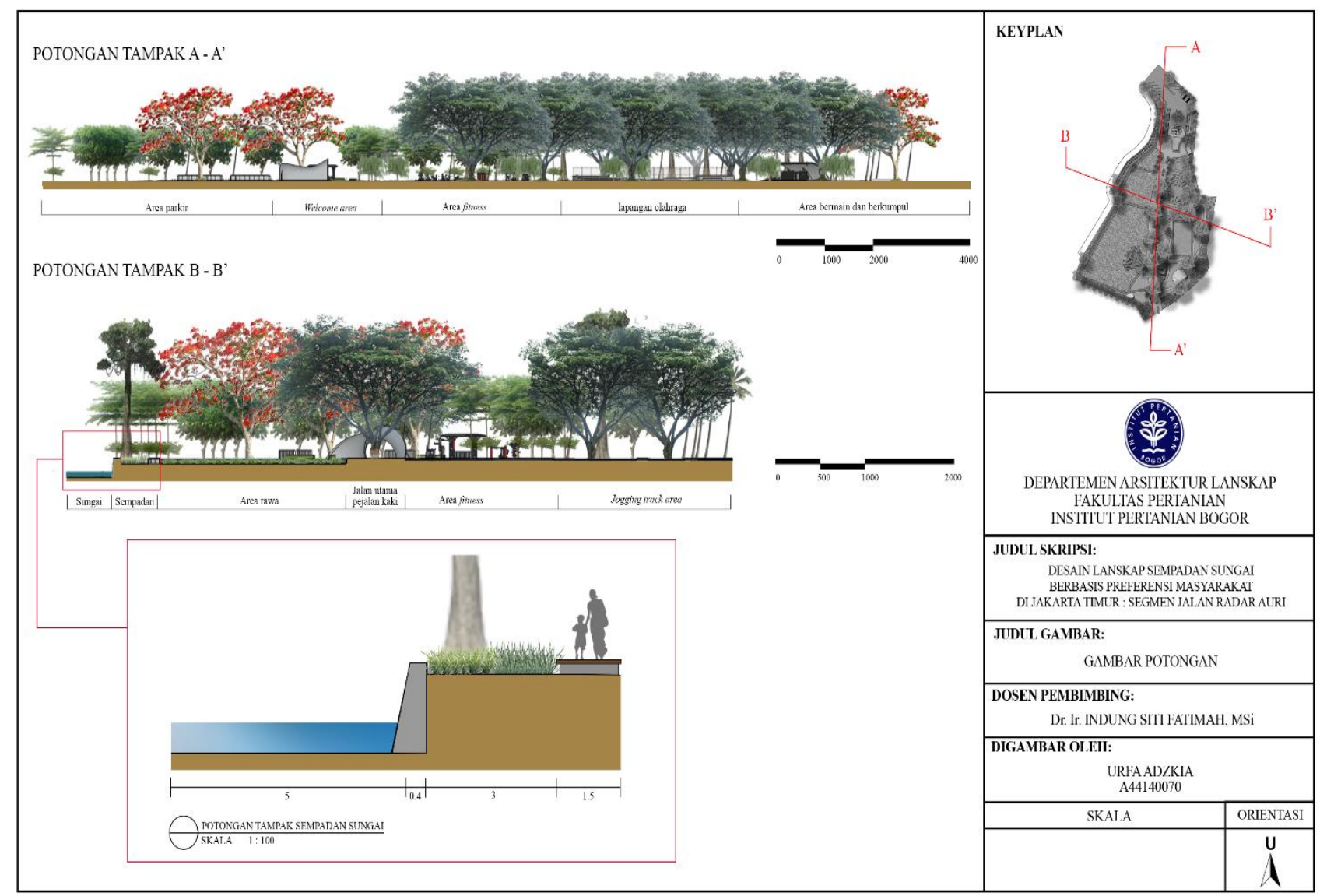

Gambar 8. Gambar Potongan Tapak.

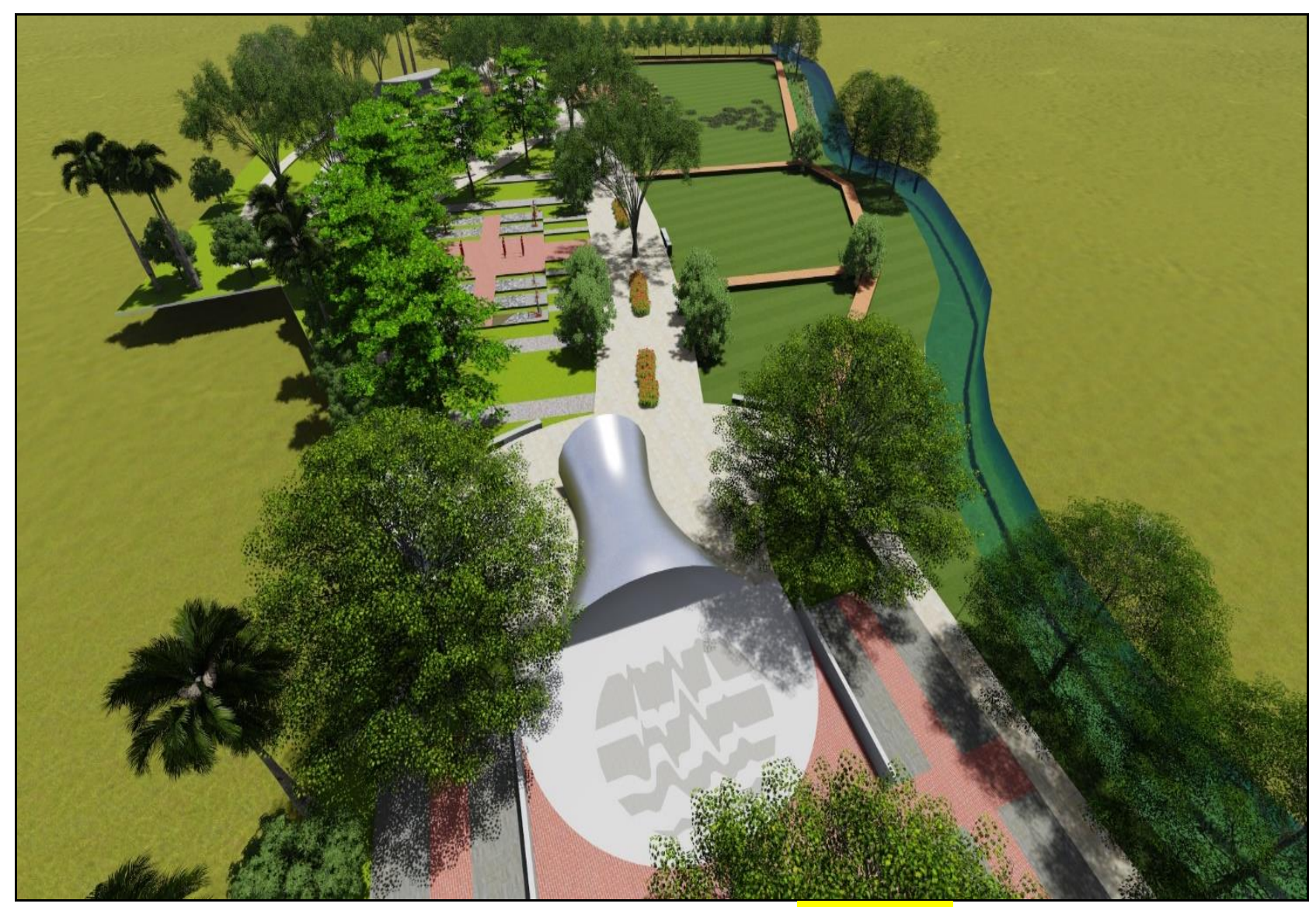

Gambar 9. Ilustrasi tampak perspektif welcome gate. 

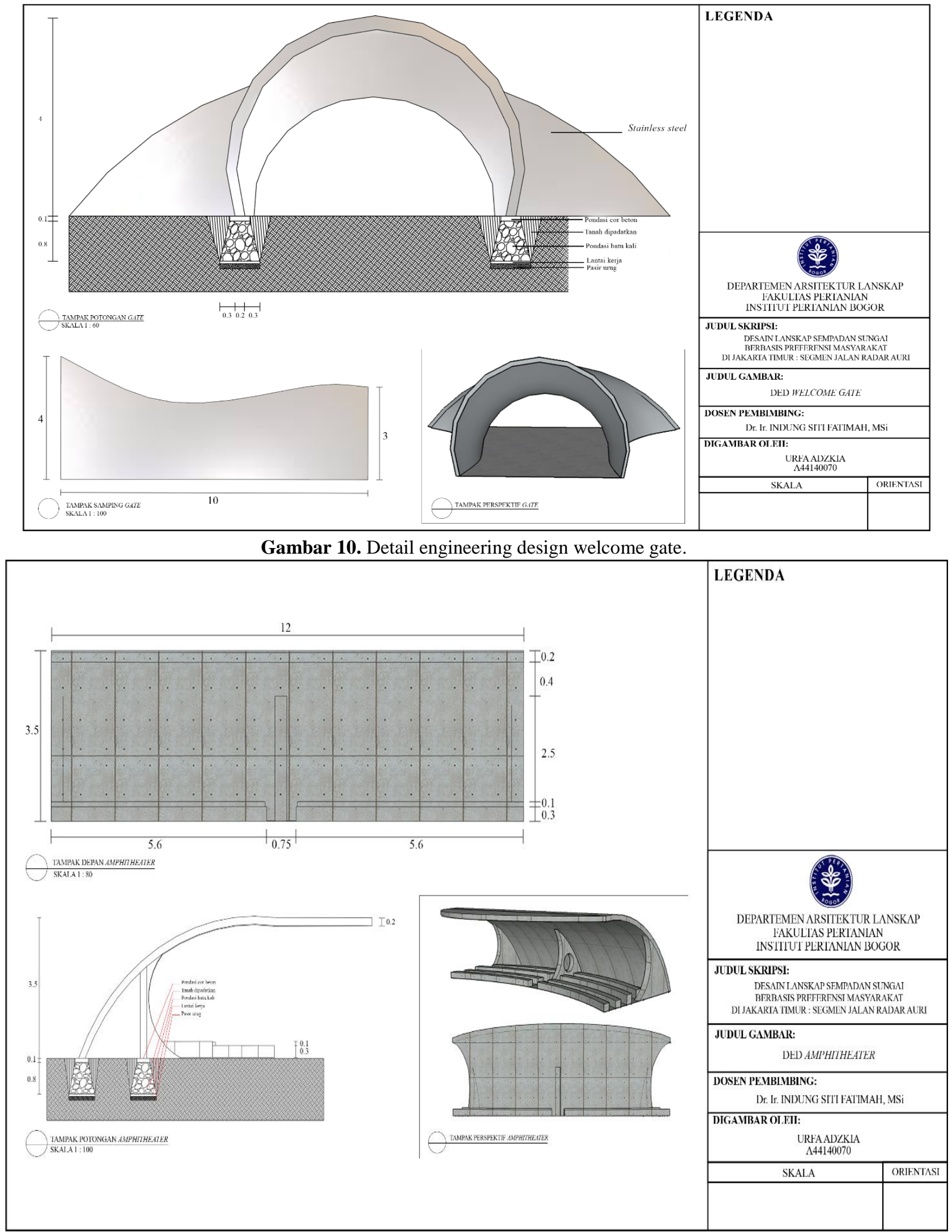

Gambar 11. DED Ampiteater.

\section{Area Bermain Anak}

Area bermain anak memiliki luas $134.5 \mathrm{~m}^{2}$, terdapat fasilitas berupa satu set permainan anak dilengkapi dengan papan seluncur, papan panjatan, jaring-jaring panjatan, dan jembatan goyang. Lantai perkerasan pada area bermain anak menggunakan lantai rubber berwarna abu-abu gela., Lantai rubber merupakan lantai berbahan karet anti slip dan 
empuk yang dapat menambah kenyamanan dan keamanan anak saat bermain. Rubber berwarna gelap dipilih untuk menghindari pantulan cahaya matahari berlebih/ kesilauan dan mengontrol iklim mikro dengan menurunkan suhu mikro. Ilustrasi area bermain anak dapat dilihat di Gambar 12.

\section{Area Olahraga}

Area olahraga (Gambar 13) berada di dekat welcome area. Terdapat fitness outdoor area dan lapangan serbaguna di sisi selatan welcome gate. Antara dua area tersebut terdapat beberapa bangku taman. Fitness outdoor area terdiri dari sepuluh alat fitness untuk body builder, dan sepuluh area therapeutic path/ foot-massaging walkway untuk pijat refleksi yang dapat diakses dari dua arah yaitu dari jalur sirkulasi utama di tengah tapak dan jogging track di sisi timur tapak. Lapangan rumput serbaguna memiliki luas $375 \mathrm{~m}^{2}$ dengan ukuran 25 x $15 \mathrm{~m}$ yang dilengkapi dengan jaring lapangan dari bahan polyethylene dengan tinggi $3 \mathrm{~m}$. Luas area olahraga $2586 \mathrm{~m}^{2}$. Lapangan ini dapat digunakan untuk kegiatan permainan bola futsal, dan segala kegiatan yang membutuhkan lahan lapang yang cukup luas.

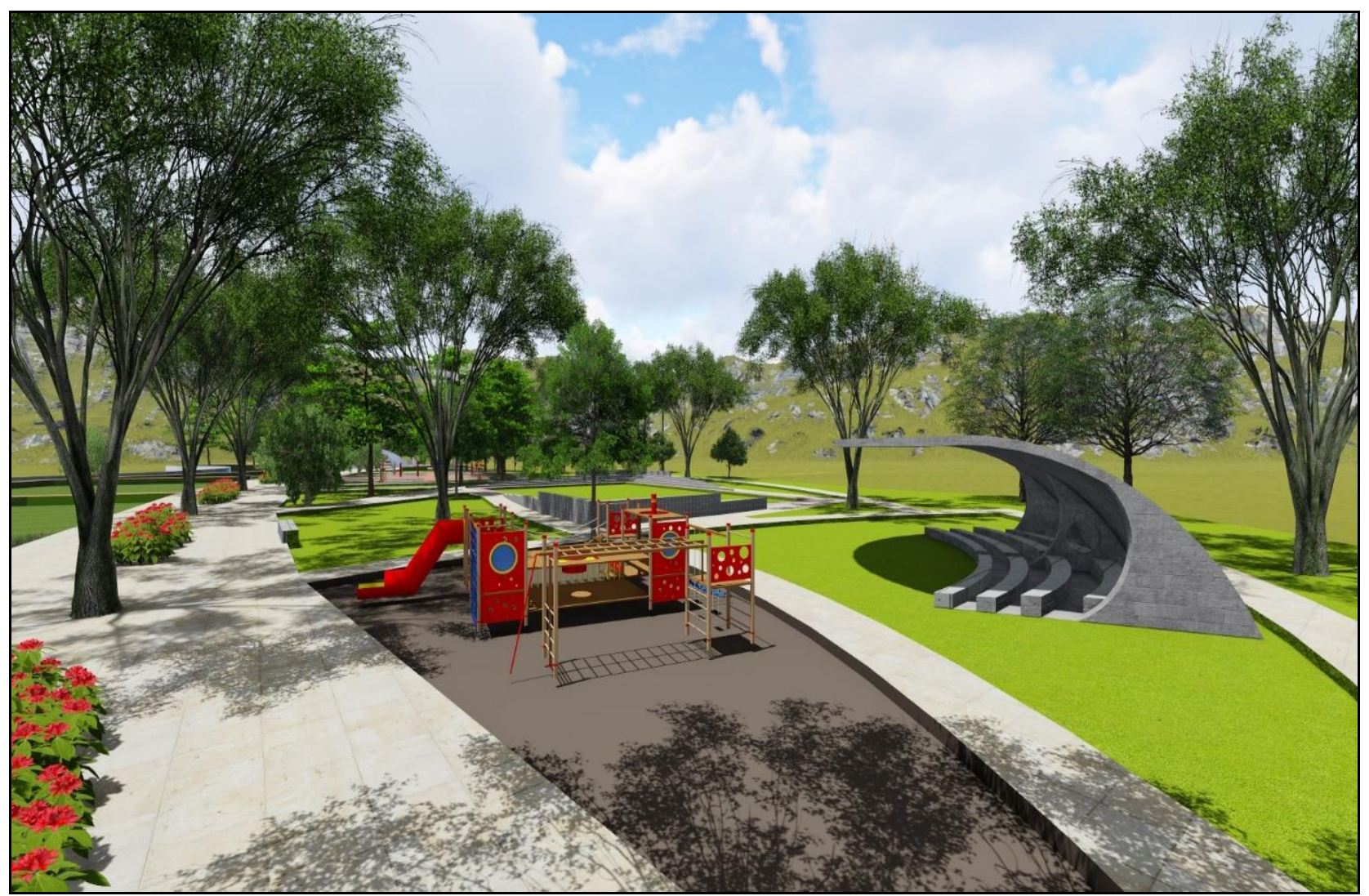

Gambar 12. Ilustrasi area bermain anak dan ampiteater.

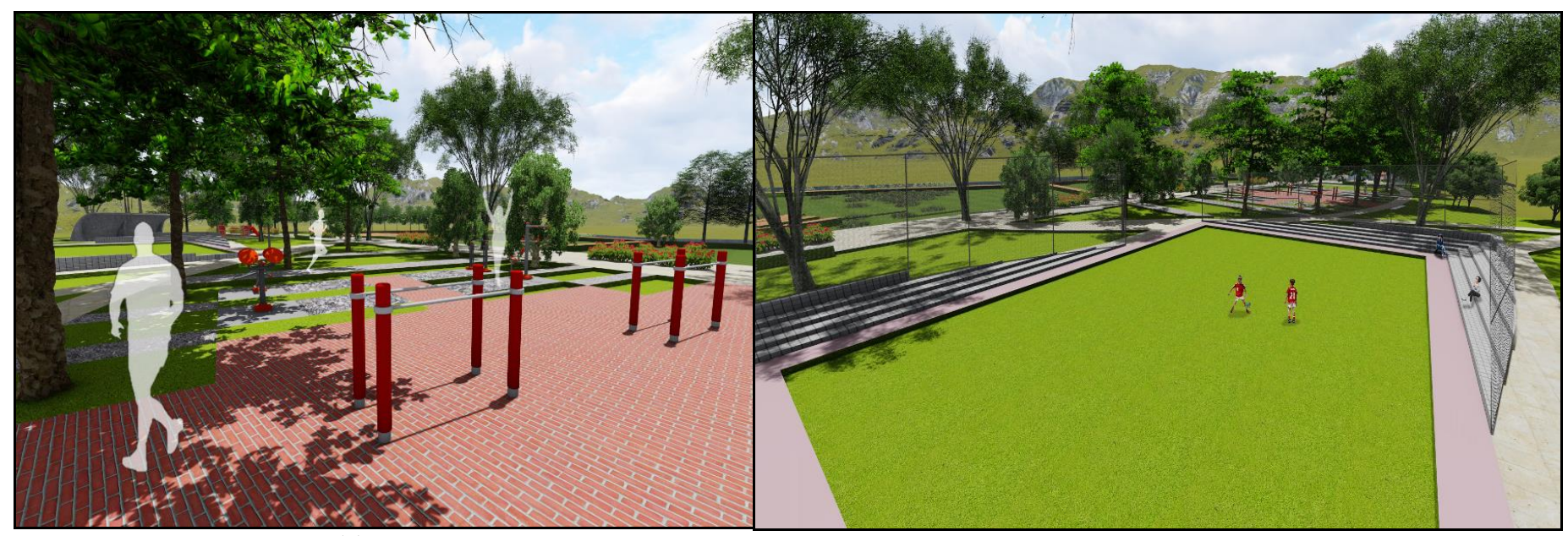

(a)

(b)

Gambar 13. Area Olahraga: (a) Ilustrasi area fitness outdoor, dan (b) Lapangan multifungsi. 


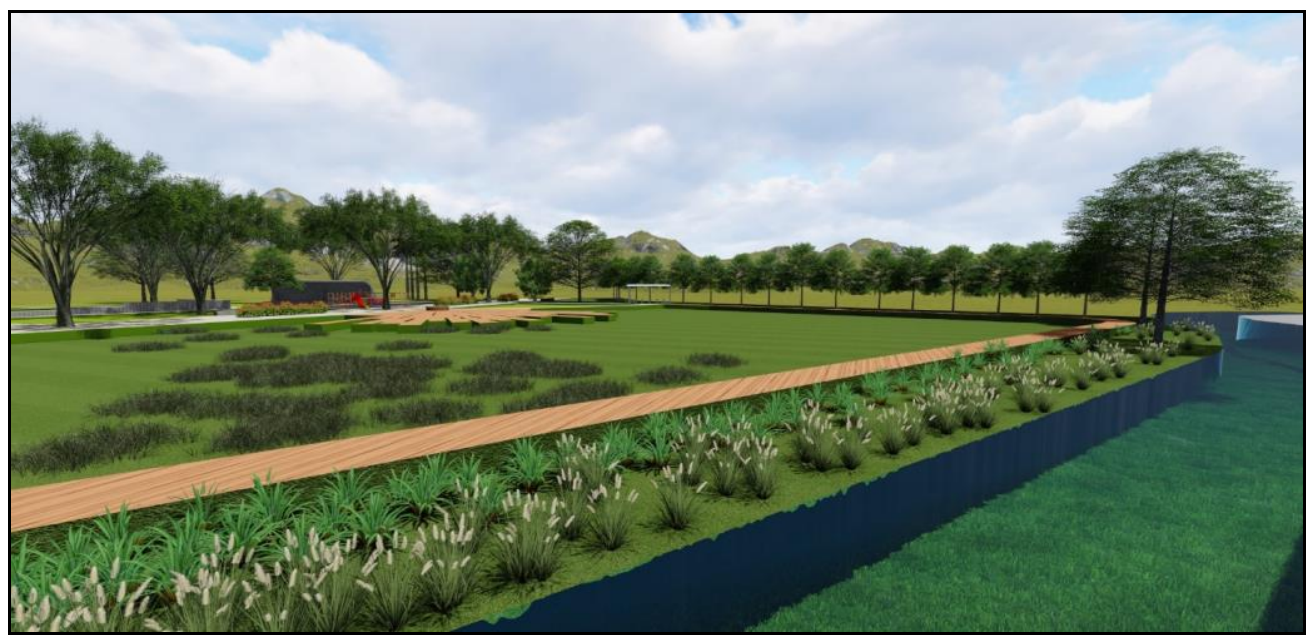

Gambar 14. Ilustrasi area konservasi.

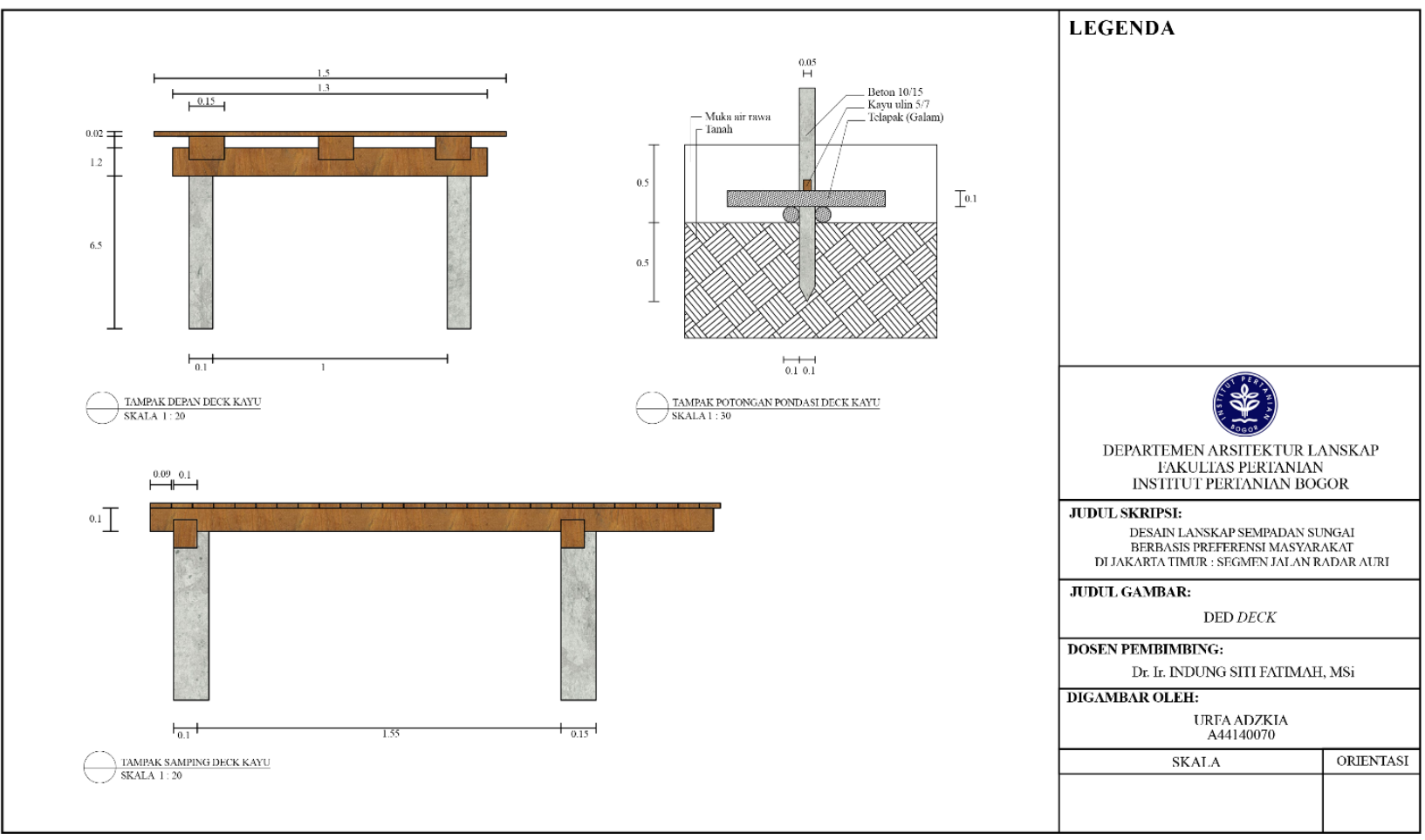

Gambar 15. DED Deck.

\section{Area Konservasi}

Area konservasi dibuat untuk tetap mempertahankan vegetasi eksisting dan mengurangi gangguan perubahan ekosistem mikro. Letaknya berada di bagian barat tapak, lahan rawa kangkung air yang memiliki luas kurang lebih 3057 $\mathrm{m}^{2}$ dipertahankan dan diberi jalur sirkulasi berupa boardwalk sebagai jalur evakuasi sempadan sungai sekaligus jalur sirkulasi bagi pengguna taman yang ingin bersantai. Pada bagian selatan tapak terdapat deck pandang dengan luas $298 \mathrm{~m}^{2}$ dipinggiran rawa. Pondasi boardwalk menggunakan pondasi tiang tongkat, pondasi ini menggunakan material kayu sebagai material utamanya. Ilustrasi area konservasi dan detail engineering design deck dapat dilihat pada Gambar 14 dan Gambar 15.

\section{KESIMPULAN}

Desain lanskap sempadan sungai Jalan Radar Auri dilakukan berdasarkan hasil preferensi masyarakat dan analisis potensi dan kendala dari berbagai aspek. Konsep "Olah Rawa (Olahraga dan Olah Jiwa)" . Desain taman ini memiliki ciri khas pada bentukan sirkulasi dengan konsep desain yang terinspirasi dari tumbuhan sayuran eksisting yaitu tumbuhan kangkung air (Ipomoea aquatica). Bentuk lengkungan pada daun diterapkan kedalam tapak, sehingga menghasilkan bentukan ruang. Terdapat lima ruang dengan beragam fungsi. Ruang parkir kendaraan bagi pengguna taman, Ruang olahraga terbagi menjadi dua lokasi, yaitu pertama area fitness dan refleksi kaki, kedua area lapangan olahraga. Children playground bertujuan untuk 
meningkatkan interaksi antar individu. Ruang berkumpul dan bersantai digunakan bagi kebutuhan hidup bersosial dan kelima adalah ruang konservasi yang memberikan fasilitas dek pandang untuk kegiatan sight-seeing. Ruang konservasi sebagai ruang yang paling dekat dengan badan sungai yang ditanami vegetasi penahan erosi.

Lanskap sempadan sungai sebaiknya dikembangkan sebagai ruang terbuka hijau publik yang didesain sesuai dengan karakter sungai dan kondisi sekitarnya untuk memenuhi kebutuhan pengguna namun tetap menjaga kelestarian lingkungan dengan konsep ramah lingkungan sehingga dapat mewujudkan lanskap yang berkelanjutan. Hasil dari penelitian ini diharapkan dapat menjadi referensi bagi Pemkot Kota Jakarta Timur bidang pertamanan dalam melakukan perancangan taman lanskap sempadan sungai.

\section{DAFTAR PUSTAKA}

Badan Pusat Statistik Kota Administrasi Jakarta Timur. 2017. Ciracas dalam Angka 2016. Jakarta (ID): BPS Kota Administrasi Jakarta Timur.

Grahn, P., and Stigsdotter, U.K., 2010. The Relation Between Perceived Sensory Dimensions of Urban Green Space and Stress Restoration. Landscape and Urban Planning, 94:264-275.

Gold, S.M., 1980. Recreation Planning and Design (McGraw-Hill Series in Landscape and Landscape Architecture). Mcgraw-Hill, New York.
Himawan, L., dan Santoni, 2019. Penataan Ruang Komersil Warga Pada Permukiman Di Bantaran Sungai Ciliwung. Architecture Innovation, 3(2): 46-72.

Jamaludin, S.N., Mohamad, N.H.N., and Thani, S.K.S.O., 2014. Designing Conducive Residential Outdoor Environment for Community: Klang Valley, Malaysia. Procedia - Social and Behavioral Sciences. AMER International Conference on Quality of Life; 1: 4-5.

Laurie, M., 1986. Pengantar kepada Arsitektur Pertamanan. Bandung (ID): Intermatra.

Mahdavinejda, M., and Abedi, M., 2012. Community-oriented Landscape Design for Sustainability in Architecture and Planning. Procedia engineering. 2011 International Conference on Green Buildings and Sustainable Cities; Elsevier; Amsterdam.

Peraturan Daerah Provinsi Daerah Khusus Ibu Kota Jakarta No. 1 tahun 2014 tentang Rencana Detail Tata Ruang dan Peraturan Zonasi.

Peraturan Pemerintah RI No. 38 Tahun 2011 tentang Sungai.

Sugiyono, 2009. Metode Penelitian Administrasi Dilengkapi dengan MetodeR\&D, Bandung (ID): CV Alfabeta.

Wardiningsih, dan Salam, B.F., 2019. Perencanaan RTH Sempadan Sungai Ciliwung di Kawasan Kampung Pulo dan Bukit Duri Jakarta, Jurnal Arsitektur, 18(1):65-74.

Zuidam, R.A., 1985. Aerial Photo-Interpretation Terrain Analysis and Geomorphology Mapping. Smith Publisher The Hague, ITC. 